\section{The Fremantle Primary Prevention Study: a multicentre randomised trial of absolute cardiovascular risk reduction}

Brett et al recently described a randomised trial of cardiovascular disease (CVD) risk reduction in three general practices. ${ }^{1}$ Suboptimal trial design may be a substantial contributor of concern about the efficacy and cost-effectiveness of such primary prevention interventions by health professionals. ${ }^{2}$ We are concerned that such shortcomings also feature in their study.

The study aimed to measure the effect on CVD risk of more frequent GP visits. The number of study visits actually received was not specified, and is crucially important. Based on a small sample, opportunistic group participants received clinically significantly more 'non-study' GP visits, ostensibly unrelated to the intervention but possibly not. Also, the study design did not allow an effect to occur between the final GP visit and data collection. Therefore, we estimate that they potentially compared a mean of 9.6 intervention group visits with a control group mean of 7.8 visits land not 5 versus 2 visits, as claimed). Similar levels of care may explain a lack of between-group differences for the primary outcome.

Counselling provided was unclear. Apart from risk measurement and target specification, GP-counselling was simply deemed 'individualised' and 'offered as appropriate' - further details would be welcomed. No framework for behavioural change is specified, nor is any protocol for initiation or intensification of drug treatment, despite potential influence on outcomes. ${ }^{2} \mathrm{~A}$ substantial practice nurse role is hinted at in the discussion section but never described.

We are also concerned by the authors conclusion that 'the study demonstrates that absolute cardiovascular risk can be improved by primary prevention strategies' This misinterprets minor land occasionally significant) improvements to individual risk factors - there was no significant betweengroup reduction in overall CVD risk. The authors also conclude that a targeted approach using absolute risk calculators can be used in primary care to modify global CVD risk assessment' - given that risk calculators were employed for both study arms, it should not be implied that this was evaluated.

Benjamin Philpot,

Statistician, Greater Green Triangle, University Department of Rural Health, Deakin University and Flinders University, Warrnambool, Australia.

Kevin McNamara,

Research Fellow, Centre for Medicine Use and Safety, Monash University, Parkville, Victoria, Australia.

E-mail: Kevin.P.McNamaraßamonash.edu

James A Dunbar,

MD, Professor, Greater Green Triangle, University Department of Rural Health, Deakin University and Flinders University, Warrnambool, Australia.

\section{REFERENCES}

1. Brett T, Arnold-Reed D, Phan C, et al. The Fremantle Primary Prevention Study: a multicentre randomised trial of absolute cardiovascular risk reduction. Br J Gen Pract 2012; DOI: 10.3399/bjgp12X616337.

2. Ebrahim S, Taylor F, Ward K, et al. Multiple risk factor interventions for primary prevention of coronary heart disease. Cochrane Database of Syst Rev 2011; (1): CD001561.

DOI: 10.3399/bjgp12X635994

\section{Authors' response}

Philpot et al have done no more than reiterate (albeit in more detail) what we have already described and discussed in the paper.' The study design as outlined in the methods clearly states that the Fremantle Primary Prevention Study was an open, prospective, pragmatic ${ }^{2}$ randomised study in three practices' involving 1200 participants with the aim of absolute cardiovascular risk reduction.

We sought to examine our intervention in the real life situation of busy clinical practices. We clearly stated that the study designated five visits for the intensive group and two for the opportunistic group and for ethical reasons we placed no restrictions on routine attendances outside of planned study visits. We have no information on whether or not relative risk cardiovascular targets were discussed at unplanned visits. It is possible that the impact of the intervention on absolute risk reduction could have been more marked if visits were restricted.

Time constraints inevitably impact on busy GPs and practice nurses in clinical practice and need to be taken into account in the design of research studies. In our study, ethical practice necessitated that clinical judgements on the efficacy of introducing or altering pharmacological treatment, referrals to a dietician, exercise physiologist, or cardiologist, were at the discretion of the treating doctor. The practice nurses played key roles in recruitment, randomisation, and follow-up of participants. ${ }^{3}$ Whether health promotion messages are effective or not would depend on who delivers the messages and how they are delivered.

Effective translational research in a general practice setting requires a pragmatic approach which inevitably leads to complexity of study design. We were pleased that so many patients engaged in the study and follow-up discussions suggest their enablement benefitted from the experience.

All research can be improved as none is perfect.

Tom Brett,

Professor and Director, General Practice and Primary Health Care Research, School of Medicine, The University of Notre Dame Australia, Fremantle, Western Australia. E-mail: tom.brettland.edu.au

Diane Arnold-Reed,

Associate Professor and Programme Coordinator, School of Medicine, The University of Notre Dame Australia, Fremantle, Western Australia.

Max Bulsara,

Professor of Biostatistics, The University of Notre Dame Australia, Fremantle, Western Australia. 


\section{REFERENCES}

1. Brett T, Arnold-Reed D, Phan C, et al. The Fremantle Primary Prevention Study: a multicentre randomised trial of absolute cardiovascular risk reduction. $\mathrm{Br} J$ Gen Pract 2012; DOI: 10.3399/bjgp12X616337.

2. MacPherson H. Pragmatic clinical trials. Complement Ther Med 2004; 12(2-3): 136-140.

3. Young J, Manea-Walley W, Mora N, et al. Practice nurses and research - The Fremantle Primary Prevention study. Aust Fam Physician 2008; 37(6): 464-466.

DOI: 10.3399/bjgp12X636001

\section{Why bother talking to teenagers?}

We applaud Samir Dawlatly's exhortation 'why bother talking to teenagers?' ${ }^{1}$ and would like to offer further commentary and clarity for those interested in working more effectively with young people consulting in primary care.

Dr Dawlatly refers to the RCGP Adolescent Primary Care Society. This group has been through numerous name-changes but is in fact known as the Adolescent Health Group (AHG [formerly the Adolescent Task Force]). The group has a long history upon that we build today. We are now part of the College's Clinical Innovation and Research Centre and more can be found out about our activities at http://www.rcgp.org.uk/clinical_and_researc $\mathrm{h} / \mathrm{circ} /$ priorities_commissioning/adolescen t_health.aspx including accessing the brand new Confidentiality Toolkit and a summary of the recent symposium on young people's mental health, a key priority area of the group.

Our three main areas of focus are education, informing policy development, and advocacy. The group's members lead on a number of different initiatives around the country that think 'outside of the box' and seek to make primary health care more youth friendly.

Young people deserve a better deal from general practice. They visit us regularly: around half of Year 10 pupils (14-15 year olds) had visited their GP in the 3 months preceding a recent survey ${ }^{2}$ but $25 \%$ of the girls reported feeling uneasy when consulting with their GP.2 The health needs of young people are also rising; with increasing use of alcohol, rates of STIs, and obesity. ${ }^{3}$ In the last few decades it is only adolescents who have seen no improvement in mortality rates with an associated rise in long-term conditions. ${ }^{4}$ Health inequalities further complicate the picture and remain a significant barrier for all young people to enjoy better health.

While we accept doctors cannot overturn the structural obstacles and transform health through the practice of medicine ${ }^{5}$ we at the $A H G$ are committed to making changes to improve the care of young people's health in primary care. We invite you to learn more about us from our webpage and our chair's blog. ${ }^{6}$

For those readers who are interested in joining the group please contact Jane Roberts.

Jane Roberts,

Chair of RCGP Adolescent Health Group, Blackhall Community Health Centre, Hesleden Road, County Durham, TS27 4LQ. E-mail: jane.robertsasunderland.ac.uk

\section{REFERENCES}

1. Dawlatly $\mathrm{S}$. Why bother talking to teenagers. $\mathrm{Br} \mathrm{J}$ Gen Pract 2012; 62(595): 94.

2. The Schools and Students Health Education Unit. Young people into 2010. Exeter: SHEU, 2010.

3. Coleman J, Brooks F, Treadgold P. Key data on adolescence 2011. London: The Association of Young People's Health, 2011.

4. Viner R, Barker M. Young people's health: the need for action. BMJ 2005; 330(7496): 901-903.

5. Edgcumbe D. Good health has little to do with doctors, Mr Lansley. Br J Gen Pract 2012; 62(595): 95.

6. Roberts J. Chair's blog for the RCGP Adolescent Health Group.

http://chairrcgpahg.blogspot.com/2011/05/welcom e-to-rcgp-adolescent-health-group.html laccessed 8 Mar 2012).

DOI: 10.3399/bjgp12X636010

\section{The one and the many}

I welcome Kramer's reflective paper ${ }^{1}$ on our work and its funding. I think he asks the right starting question, and that the answering questions go deeper still. They are obvious to any astute observer of general practice, and they are begging to be answered in every surgery we each do. Medical and other politicians are begging not to answer them as they are too difficult, and so stop them being 'pragmatic'?

They centre around the old philosophical problem of how we balance the needs and wants of the one with the needs and requirements of the many. So for example in morning surgery should we give our first patient an excellent thorough consultation 